\title{
Is the medial amygdala part of the neural circuit modulating conditioned defeat in Syrian hamsters?
}

\author{
Chris M. Markham ${ }^{1}$ and Kim L. Huhman \\ Department of Psychology, Georgia State University, Atlanta, Georgia 30302, USA
}

\begin{abstract}
Conditioned defeat is a model wherein hamsters that have previously experienced a single social defeat subsequently exhibit heightened levels of avoidance and submission in response to a smaller, non-aggressive intruder. While we have previously demonstrated the critical involvement of the basolateral and central nuclei of the amygdala in the acquisition and expression of conditioned defeat, the role of the medial amygdala has yet to be investigated. In Experiment 1 , muscimol, a $G A B A_{A}$ receptor agonist, was infused bilaterally into the MeA prior to initial defeat training. Experiment 2 examined the effects of muscimol injections given prior to subsequent testing with a non-aggressive intruder. Finally, in Experiment 3, anisomycin was used to block protein synthesis in the medial and basolateral amygdala to examine the involvement of these nuclei in memory consolidation related to conditioned defeat. Submissive behavior was significantly reduced in animals that received muscimol prior to initial defeat training as well as in animals injected prior to testing with the non-aggressive intruder, indicating that the MeA is necessary for the acquisition and expression of conditioned defeat. In Experiment 3, however, anisomycin reduced conditioned defeat only when administered into the BLA, and not when injected into the MeA. The results of the present series of experiments suggest that, while the MeA may serve an important gateway for sensory information that is crucial for conditioned defeat, it does not appear to play a role in the plasticity including this behavioral response to social defeat.
\end{abstract}

Social conflict is a powerful experience that contributes to the establishment of dominant-subordinate hierarchies in many species and produces a host of physiological and behavioral changes, particularly in the defeated animal. For example, social defeat and subordination stress result in increased levels of plasma adrenocorticotrophin (ACTH) and glucocorticoids (Huhman et al. 1991; Blanchard et al. 1993, 1995), reduced levels of testosterone (Huhman et al. 1991; Blanchard et al. 1995) and immune functioning (Jasnow and Huhman 2001), and changes in body weight (Blanchard et al. 1995; Foster et al. 2006; Solomon et al. 2007). Behaviorally, social defeat has been shown to heighten levels of fear and anxiety-related behaviors such as freezing and risk assessment (Blanchard and Blanchard 1990) while reducing aggression and reproductive behavior (Blanchard and Blanchard 1990; Blanchard, et al. 1993, 1995).

For the past several years, our laboratory has used an ethologically relevant model of social stress called conditioned defeat (Potegal et al. 1993) in Syrian hamsters (Mesocricetus auratus). Hamsters are an ideal species with which to study social defeat because they are solitary animals and are highly territorial. In a laboratory environment, a resident hamster will reliably attack and defeat an intruder placed into its home cage. Subsequently, however, the defeated animal instead produces only high levels of submissive and defensive behaviors (flight, upright defense, tail lift) and no aggressive behavior even when a smaller, nonaggressive intruder is placed into its own home cage. This behavioral response to social defeat is prolonged, lasting at least $1 \mathrm{mo}$ in the majority of animals (Huhman et al. 2003).

Although the neurobiological mechanisms underlying conditioned defeat are just beginning to be elucidated, the neural systems underlying conditioned fear in more controlled, but perhaps less biologically relevant, models have been well characterized. A large number of studies have implicated the amygdala as

${ }^{1}$ Corresponding author.

E-mail psycmm@langate.gsu.edu; fax (404) 651-3929.

Article is online at http://www.learnmem.org/cgi/doi/10.1101//m.768208. a key structure mediating the acquisition and expression of conditioned fear. For example, both pre- and post-training lesions of the central and basolateral complex of the amygdala decrease conditioned freezing to shock or to contextual cues paired with shock (Blanchard and Blanchard 1972; LeDoux et al. 1990; Roozendaal et al. 1991; Helmstetter 1992; Phillips and LeDoux 1992; Sananes and Davis 1992). Together, these studies indicate that the amygdala plays an essential role in fear learning. Indeed, the basolateral complex (BLA) is believed to function as the convergence point for sensory input related to conditioned fear as well as serving as an important site for synaptic plasticity (Fanselow and LeDoux 1999). Several studies have shown that infusion of the NMDA receptor antagonist DL-2-amino-5phosphonopentanoic acid (AP5) into the BLA blocks the acquisition of conditioned freezing and fear-potentiated startle (Campeau et al. 1992; Gewirtz and Davis 1997; Lee and Kim 1998), and subsequent studies have implicated the NR2B subunit of the NMDA receptor complex in the BLA as playing an especially important role in the plasticity underlying conditioned fear (Tang et al. 1999; Rodrigues et al. 2001; Rattiner et al. 2004). Additionally, more recent studies are beginning to implicate the BLA as the site of LTP-like mechanisms that may underlie the cellular basis of conditioned fear (LeDoux 2000; Maren 2001). Finally, site-specific injections of anisomycin, a protein synthesis inhibitor, into the BLA impair the acquisition of auditory fear conditioning in a dose-dependent manner (Schafe and LeDoux 2000), presumably via its blockade of cellular processes necessary for the formation of long-term memory (Bourtchouladze et al. 1998; Schafe and LeDoux 2000; Parsons et al. 2006).

Although conditioned fear has proven to be invaluable in elucidating the neurobiological mechanisms underlying emotional learning and plasticity, one drawback of the traditional models is the use of an artificial, unimodal stimulus (such as electric shock or a loud sound) to elicit fear responses. On the other hand, conditioned defeat is an ethologically relevant model of fear, wherein animals are allowed to freely interact in a 
seminatural environment. Conditioned defeat therefore provides an opportunity to study conditioned fear in response to more natural, multimodal cues, allowing us to potentially study a broader neural circuit than is possible with many other models of conditioned fear.

Using our social defeat model, we have demonstrated that the amygdala is critically involved in the acquisition and expression of conditioned defeat. Temporary inactivation of the central (CeA) and basolateral complex of the amygdala via muscimol injections causes a reduction in submissive behavior in animals that have been previously defeated (Jasnow and Huhman 2001). Additionally, blockade of the NR2B receptor subunit in the BLA specifically disrupts the acquisition, but not expression, of conditioned defeat (Day et al. 2004). These results are consistent with studies using traditional models of conditioned fear such as classical Pavlovian fear conditioning and fear-potentiated startle and support the hypothesis that conditioned defeat is an ethologically relevant form of fear conditioning. While there is substantial evidence implicating the CeA and BLA in the acquisition and expression of conditioned fear and conditioned defeat, there is relatively little research focusing on the other subnuclei of the amygdala, most notably the medial nucleus (MeA). Indeed, the vast majority of studies examining the MeA have focused on its role in the detection and modulation of biologically relevant odors, including those related to reproductive (Lehman and Winans 1982; Newman 1999; Meredith and Westberry 2004) and defensive behaviors (Dielenberg and McGregor 2001; Dielenberg et al. 2001; Canteras 2002; Li et al. 2004; Markham et al. 2004; Blanchard et al. 2005; Muller and Fendt 2006).

In addition to its role in the detection of biologically relevant odor stimuli, evidence is beginning to indicate that the MeA may also serve a modulatory role in certain types of fear conditioning. For example, Luiten et al. (1985) were among the first to demonstrate a role of the MeA in conditioned fear. Although this study did not specifically examine the role of biological odorants in conditioned fear, it nevertheless showed that lesions of the MeA blocked conditioned avoidance of a dominant opponent in defeated rats. These, and other (Li et al. 2004; Markham et al. 2004), studies suggest that the MeA may function specifically as a modulator of conditioned fear related to odor cues. Another study by Walker et al. (2005) found that infusion of both the AMPA/kainate receptor antagonist NBQX and the NMDA receptor antagonist AP5 into the MeA failed to disrupt fear conditioning to an olfactory conditioned stimulus (CS). In contrast, pretest infusion of NBQX into the MeA blocked the expression of fear-potentiated startle. These results suggest that the MeA is only involved in the expression, but not acquisition, of conditioned fear. However, it is also possible that the lack of effect seen on conditioning in the Walker study can be attributed to the use of amyl acetate, a non-biological odor stimulus. Considering the high degree of connectivity between the accessory olfactory bulb and the MeA (the vomeronasal pathway), the use of a more biologically relevant odor stimulus, such as that associated with a conspecific, may be more appropriate.

Experimental evidence has therefore clearly indicated the importance of the BLA in the acquisition and/or expression of conditioned fear using a variety of models including conditioned defeat, fear-potentiated startle, and conditioned freezing. However, as stated above, very few studies have examined how other subnuclei of the amygdala may also be involved in these processes. Thus, in the present study, we first tested whether the $\mathrm{MeA}$ is a component of the neural circuitry for conditioned defeat. In Experiments 1 and 2, we tested this hypothesis by microinfusing the $\mathrm{GABA}_{\mathrm{A}}$ agonist muscimol into the MeA either prior to initial defeat (acquisition phase) or prior to testing with a non-aggressive intruder (expression phase). Next, we asked whether memory consolidation for social defeat occurs in the MeA or the BLA. This was tested in Experiment 3 by microinfusing the protein synthesis inhibitor anisomycin into either the MeA or BLA prior to the acquisition phase (initial defeat training).

\section{Results}

\section{Experiment 1: Effect of muscimol in the MeA on acquisition of conditioned defeat}

Figure 1 shows the injection sites for animals in Experiment 1. The injection needles were localized within $0.3 \mathrm{~mm}$ of the medial amygdala in 23 of the 42 cannulated animals. Other subjects had cannula placements that missed the MeA bilaterally $(n=7)$ but were located between $0.30 \mathrm{~mm}$ and $0.50 \mathrm{~mm}$ from the MeA. These animals were included in an anatomical control group. The remaining animals had unilateral placements $(n=6)$, or the infusion sites could not be verified because of occluded cannula at the time of the dye injection $(n=6)$, and these animals were removed from the study.

Animals receiving $1.1 \mathrm{nmol}$ (low dose) and $2.2 \mathrm{nmol}$ (high dose) of muscimol displayed a significant reduction of conditioned defeat-related behaviors, including less submissive/ defensiveness and higher levels of social investigation compared to the vehicle group ( $P<0.01$ and $P<0.05$, respectively) (Fig. 2$)$. No significant differences were observed between the two muscimol groups. Non-social behaviors showed no significant differences for all groups, regardless of dose, and no instances of aggression were found. Additionally, behavioral analysis of the ana-

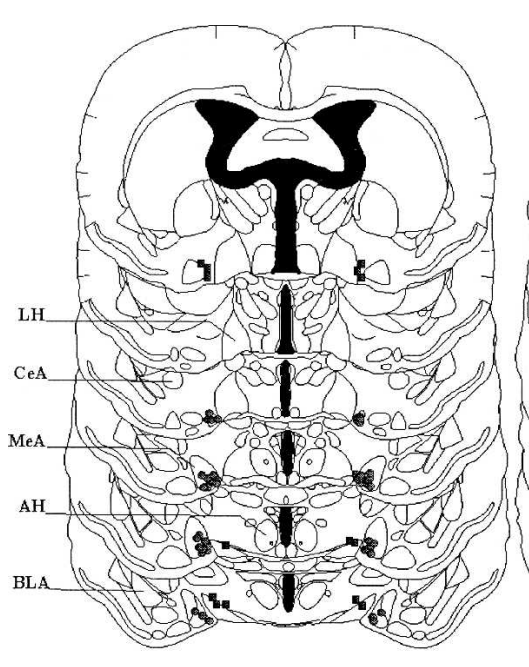

A

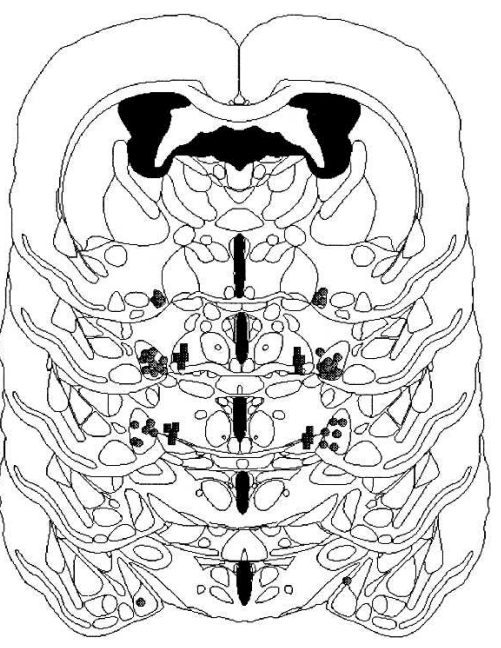

B

Figure 1. $(A, B)$ Histological reconstructions of injection sites for animals receiving infusions of muscimol into the MeA in Experiments $1(A)$ and $2(B)$. (Black dots) The site of injection into the MeA; (squares) anatomical controls (misplaced injection sites). Key neuroanatomical sites are labeled, as indicated: (LH) lateral hypothalamus; (CeA) central amygdala; (MeA) medial amygdala; (AH) anterior hypothalamus; (BLA) basolateral amygdala. Drawings are adapted from Morin and Wood (2001. 


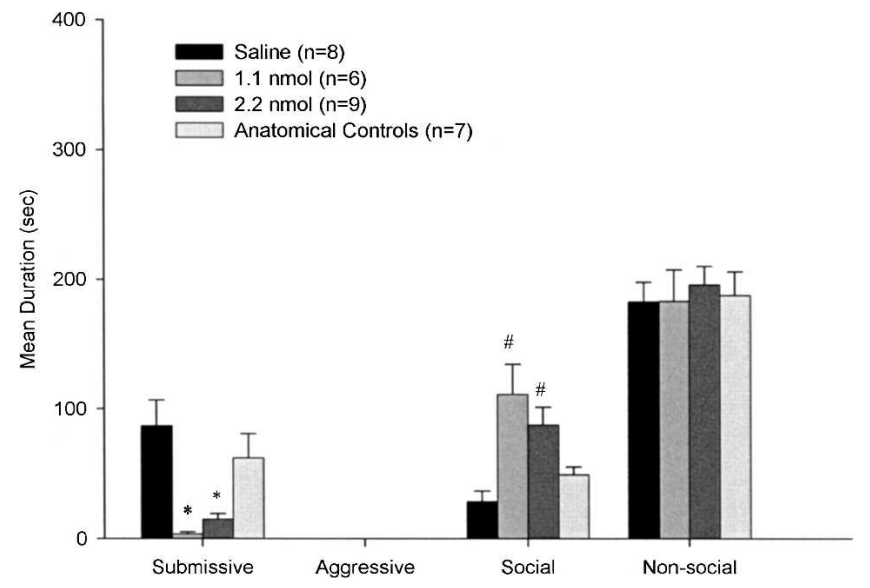

Figure 2. Total duration (mean \pm SEM) of behaviors exhibited during the 5-min test with a non-aggressive intruder (NAI). Animals received bilateral infusions of muscimol or saline into the MeA immediately prior to being defeated for 15 min. Significant differences $\left(^{*}\right) P<0.01$ and (\#) $P<0.05$ compared to vehicle controls. The rightmost bar indicates anatomical controls, or injection sites localized $>0.3 \mathrm{~mm}$ from the target.

tomical controls (injection sites localized $0.3-0.5 \mathrm{~mm}$ from the $\mathrm{MeA}$ ) showed no statistical difference from the vehicle control group, indicating that the effects of muscimol in the MeA on conditioned defeat were highly site-specific.

As indicated in Table 1, the resident aggressor (RA) was equally likely to attack the muscimol and vehicle control groups, as shown by the latency to first attack and total attack duration times, indicating that muscimol infusions did not alter the normal behavioral profile of the resident aggressors toward the experimental animals.

\section{Experiment 2: Effect of muscimol in the MeA on expression of conditioned defeat}

Figure 3 shows the injection sites for animals in Experiment 2. The injection needles were localized within $0.3 \mathrm{~mm}$ of the MeA in 24 of the 40 cannulated animals. Subjects with cannula placements that missed bilaterally by $0.3-0.5 \mathrm{~mm}(n=8)$ were included in an anatomical control group. The remaining animals had either unilateral placements $(n=4)$ or the infusion sites could not be verified $(n=4)$ because of occluded cannula at the time of the dye injection, and the data from these animals were not included in the subsequent analysis.

Animals receiving both doses of muscimol showed significantly lower levels of submissive behaviors compared with animals in the control group $(P<0.01)$ (Fig. 3). In addition, animals receiving both the 1.1- and 2.2-nmol dose displayed significantly lower levels of social behavior compared to vehicle controls $(P<0.05)$. No significant differences were found between the two muscimol groups. Non-social behaviors were not different among all groups, regardless of dose, and no instances of aggression were found. Furthermore, as with Experiment 1, behavioral analysis of the anatomical controls (injection sites localized at least $0.3 \mathrm{~mm}$ from the MeA) showed no statistical difference compared to the vehicle control group, indicating that the effects of muscimol on conditioned defeat were site-specific.

\section{Experiment 3: Effect of anisomycin in the BLA or MeA on acquisition of conditioned defeat}

Figure 4A shows the injection sites for the BLA animals in Experiment 3. Of the 20 BLA animals, 13 had bilateral placements in the BLA. Four subjects had bilateral injections and were used as anatomical controls. In addition, the head cap fell off two subjects, and one additional animal showed high levels of aggression during the training process and was not defeated. These animals were not included in the subsequent analysis and were removed from the study. Figure 4B shows the injection sites for the MeA animals in Experiment 3. Of the $24 \mathrm{MeA}$ animals, 15 showed injection sites localized bilaterally in the MeA. Seven animals had unilateral placements and were thus not included in the analysis. The remaining animals $(n=3)$ had occluded cannula during ink injection, and therefore cannula placement could not be verified; data from these animals were also removed from the study. Because there were no bilaterally misplaced cannulas in this group, an anatomical control group was not included.

Behavioral data from vehicle-administered animals in both the BLA and MeA groups were combined, as there was no significant difference between the two. In the BLA, the injection of anisomycin before training caused a significant reduction in submissive/defensive behaviors $(P<0.01) 24 \mathrm{~h}$ later at testing. These animals also showed an increase in social behavior $(P<0.05)$ compared to vehicle controls (Fig. 5). Non-social and aggressive behaviors were not significantly different compared to controls. In the MeA, anisomycin given before defeat training did not have significant effects on submissive/defensive, aggressive, and social or non-social behavior compared to control animals. Behavioral analysis of the anatomical controls for BLA animals infused with anisomycin showed no significant difference with the vehicle control group.

As indicated in Table 2, the RA was equally likely to attack the anisomycin and vehicle control groups, as shown by the latency to first attack and total attack duration times, indicating that anisomycin infusions did not alter the normal behavioral profile of the animals. Additionally, there was no difference in the behavior of the RA toward the animals given anisomycin in the BLA versus the MeA.

\section{Discussion}

The MeA has long been known to play a key role in the processing of biologically relevant odors, specifically those related to reproductive success. There are few studies examining the potential contribution of the MeA to conditioned fear. The primary aim of Experiments 1 and 2 was to examine this possibility by temporarily inactivating the MeA with the $\mathrm{GABA}_{\mathrm{A}}$ agonist muscimol and testing the animals in an ethologically relevant model of conditioned fear, in which chemosensory cues are most likely involved. The results demonstrate that infusion of muscimol into the MeA interfered with both the acquisition and expression of conditioned defeat. Specifically, in Experiment 1, animals receiving bilateral infusions of muscimol into the MeA 5 min prior to initial defeat training showed significantly fewer submissive/ defensive behaviors when paired with a non-aggressive intruder $24 \mathrm{~h}$ later than did animals receiving infusions of saline. Similarly, in Experiment 2, infusions of muscimol prior to testing with the non-aggressive intruder also resulted in a significant reduction in submissive/defensive behaviors compared to vehicle controls. These data provide support for the view that the amyg-

Table 1. Total attack duration and latency to first attack of resident aggressors during training in Experiment 1

\begin{tabular}{lcc}
\hline Experimental condition & $\begin{array}{c}\text { Latency to } \\
\text { first attack }(\mathrm{sec})\end{array}$ & $\begin{array}{c}\text { Total attack } \\
\text { duration }(\mathrm{sec})\end{array}$ \\
\hline $\begin{array}{l}\text { Saline control }(0 \mathrm{nmol}) \\
\text { Muscimol }\end{array}$ & $23.3 \pm 9.8$ & $181.2 \pm 77.7$ \\
$\quad$ Low dose $(1.1 \mathrm{nmol})$ & $28.7 \pm 5.2$ & $199.8 \pm 41.6$ \\
High dose $(2.2 \mathrm{nmol})$ & $61.0 \pm 23.2$ & $211.6 \pm 55.6$ \\
\hline
\end{tabular}




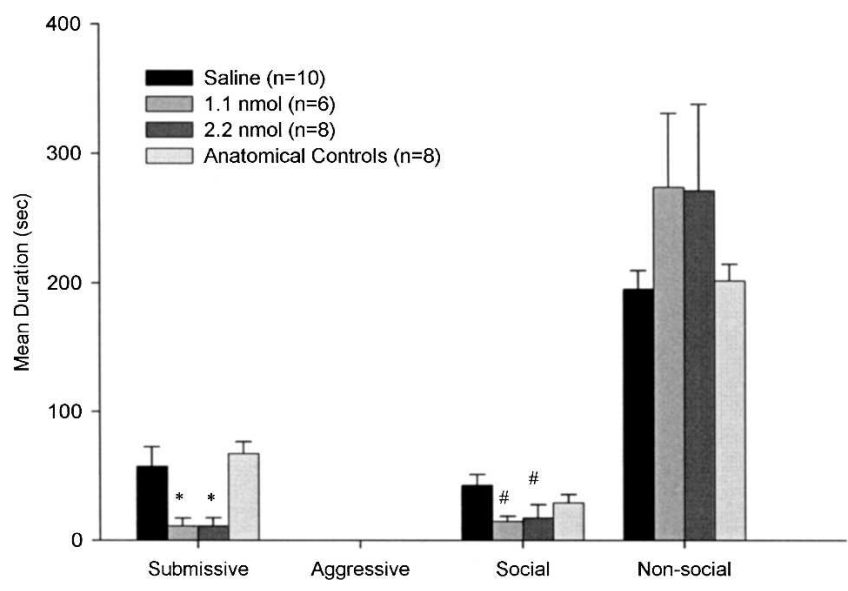

Figure 3. Total duration (mean \pm SEM) of behaviors exhibited by defeated animals during the 5-min test with a non-aggressive intruder (NAI). Animals received bilateral infusions of muscimol or saline into the MeA immediately prior to testing with the NAI. Significant differences $\left(^{*}\right)$ $P<0.01$ and (\#) $P<0.05$ compared to vehicle controls. The rightmost bar indicates anatomical controls, or injection sites located $>0.3 \mathrm{~mm}$ from the target.

dala is a critical component of the neural circuitry modulating conditioned fear in general (Blanchard and Blanchard 1972; LeDoux et al. 1990; Jasnow and Huhman 2001; Nader et al. 2001; Davis 2006) and demonstrate for the first time that the MeA is a critical component of the neural circuit that controls conditioned defeat.

In Experiment 1, animals receiving both doses of muscimol (1.1 and $2.2 \mathrm{nmol}$ ) prior to the acquisition of conditioned defeat displayed significantly lower levels of submissive/defensive behaviors compared to controls, and, importantly, these animals also showed a concomitant increase in pro-social behaviors, including chemosensory investigation of the NAI. This bidirectional effect strongly points to a specific reduction in the acquisition of conditioned defeat rather than a general inhibition of social or locomotor activity. Additionally, analysis of the training (defeat) sessions revealed no significant differences in the aggressive behavior of the resident aggressors toward muscimol- and saline-infused subjects, reducing the likelihood that muscimol infusions somehow altered the stimulus properties of the subjects, thus adversely affecting the normal attack pattern of the RAs. In Experiment 2, muscimol infusions (both 1.1- and 2.2-nmol doses) prior to testing with the NAI ( $24 \mathrm{~h}$ after initial defeat) also caused a significant reduction in submissive/defensive behaviors. However, unlike Experiment 1 where a concomitant increase in prosocial behaviors was observed, making it unlikely that a non-specific or carryover effect had occurred, no such increase was found in Experiment 2. Indeed, muscimol injections significantly decreased social behaviors, and a slight, although non-significant, increase in nonsocial behaviors (including grooming and digging into the corncob bedding) was observed compared to saline controls. However, the overall reduction in (2001). conditioned defeat did not appear to be due to a non-specific, sedative-like effect of muscimol on behavior.

The effect of muscimol infusions on the acquisition and expression of conditioned defeat also appears to be anatomically specific to the medial nucleus of the amygdala. Infusions of muscimol that were centered in areas $>300-500 \mu \mathrm{m}$ from the MeA had no significant effect on either the acquisition or expression of conditioned defeat, as these animals showed levels of conditioned defeat similar to controls. Additionally, behavioral data in subjects with unilateral cannulations (either the right or left side) showed an intermediary, although not statistically significant, effect of muscimol on conditioned defeat (data not shown). Finally, animals in the anatomical control group in Experiment 2 did not show an apparent increase in non-social behavior further indicating that muscimol at the doses used in this study does not induce non-specific, ataxic effects on behavior.

Of particular interest are the results from Experiment 1, which demonstrate the involvement of the MeA on the acquisition of conditioned fear using an ethologically relevant model of conditioned fear. Two possible interpretations emerge from these results. The first is that plasticity for biologically relevant odor cues occurs specifically in the MeA, while the BLA mediates the consolidation of fear-related memories. This viewpoint is supported by studies showing a lack of effect of MeA lesions using traditional models of conditioned fear. For example, Nader et al. (2001) showed that while lesions of the CeA and LA (lateral nucleus of the amygdala), or of the entire amygdala, disrupted the acquisition of auditory fear conditioning, lesions of the MeA had no effect. Additionally, Oakes and Coover (1997) showed that lesions of the MeA did not adversely affect a drinking passive-avoidance (dPA) learning task, while lesions of the CeA significantly attenuated dPA. Finally, a more recent study showed that infusions of AP5 into the MeA caused a disruption in the expression, but not acquisition of fear conditioning to an olfactory cue (Walker et al. 2005). Conversely, however, the study by Luiten et al. (1985) showed that lesions of the MeA in previously defeated rats caused a decrease in active avoidance of male con-

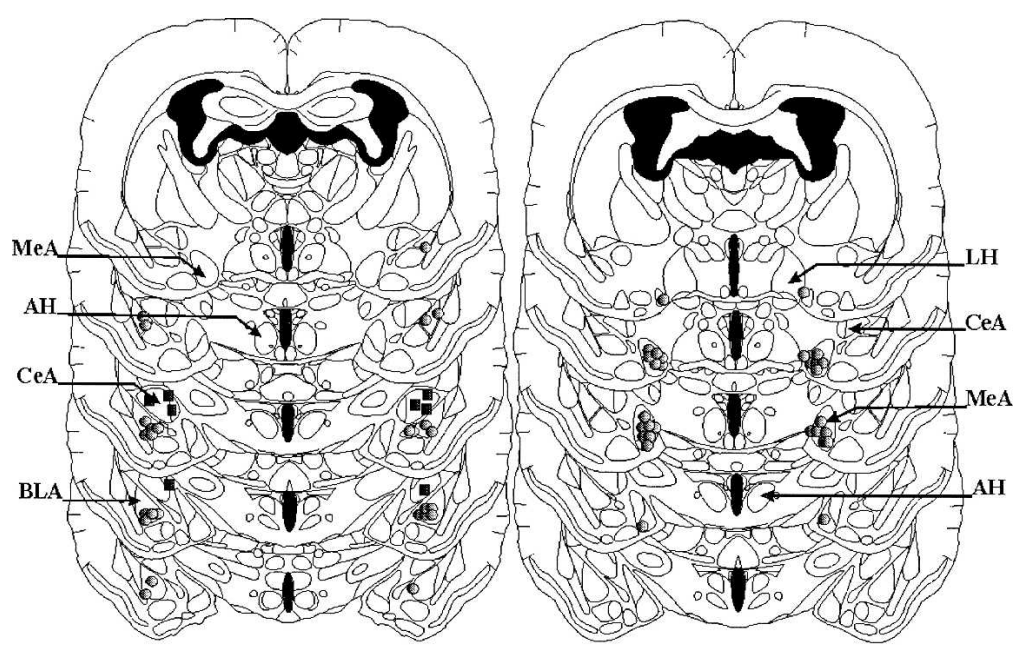

A

Figure 4. $(A, B)$ Histological reconstructions of injection sites for animals receiving infusions of anisomycin into the $(A)$ BLA or $(B)$ MeA in Experiment 3. (Black dots) The site of injection into either the BLA or MeA; (squares) anatomical controls (misplaced injection sites). Key neuroanatomical sites are labeled, as indicated: (MeA) medial amygdala; ( $\mathrm{LH}$ ) lateral hypothalamus; $(\mathrm{AH})$ anterior hypothalamus; (CeA) central amygdala; (BLA) basolateral amygdala. Drawings are adapted from Morin and Wood 


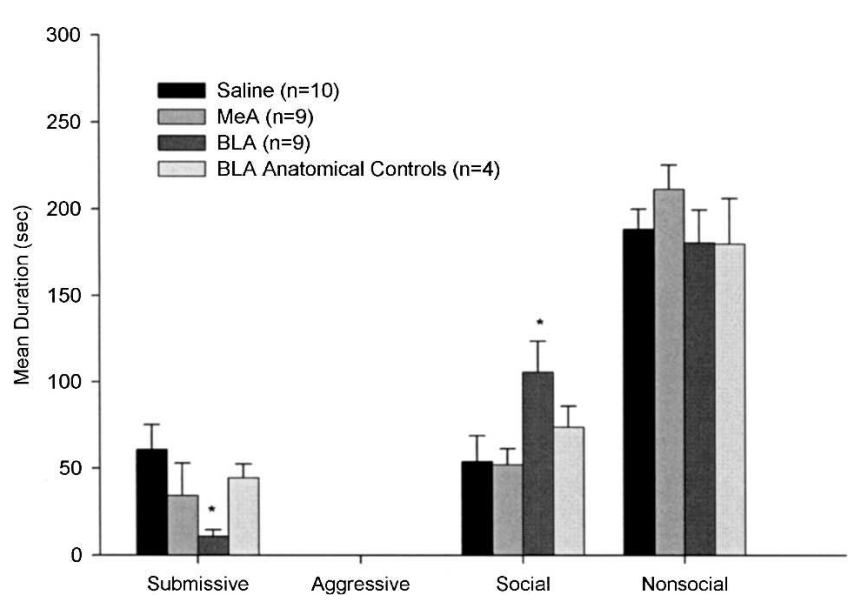

Figure 5. Total duration (mean \pm SEM) of behaviors exhibited during the 5-min test with a non-aggressive intruder (NAI). Animals received bilateral infusion of anisomycin $(0.75 \mathrm{nmol}$ per side) into either the BLA or MeA immediately prior to being defeated for $15 \mathrm{~min}$. Significant differences (*) $P<0.01$ compared to vehicle controls. The rightmost bar indicates anatomical controls for BLA animals, with injection sites localized $>0.3 \mathrm{~mm}$ from the target.

specifics, suggesting that fear of a previously dominant conspecific is dependent on the MeA. The results from Experiments 1 and 2 confirm and extend these findings in that a significant decrease in submissive/defensive behaviors was observed in muscimol-infused animals exposed to the NAI. One possible interpretation for these contradictory findings is that the present study as well as the Luiten study used an ethological approach, which involves biological odors, to investigate the role of the MeA in fear conditioning. Conversely, other studies suggesting a lack of involvement of the MeA in fear conditioning used more traditional, non-social approaches and non-biological odorants, such as amyl acetate, as the conditioned stimulus (Walker et al. 2005).

Another possible interpretation is that the MeA may simply communicate necessary chemosensory stimuli associated with socially relevant odors to other areas of the amygdala, such as the BLA, and that the BLA is actually the crucial site required for consolidation of all fear-related plasticity. Thus, the goal of Experiment 3 was to specifically address this possibility by infusing anisomycin, a protein synthesis inhibitor, into either the MeA or BLA during the acquisition phase of conditioned defeat. If plasticity related to socially relevant odor cues occurs in the MeA, then anisomycin infusions in the MeA should disrupt the consolidation process and interfere with conditioned defeat.

The results of Experiment 3 showed that the infusion of anisomycin into the MeA prior to initial defeat training failed to disrupt submissive/defensive behaviors, but that infusions into the BLA significantly reduced these behaviors. These results strongly suggest that the MeA is not a crucial site for the consolidation of fear-related memories that underlie conditioned defeat and are consistent with previous findings on several levels. First, several studies have shown that the site of neural plasticity in-

Table 2. Total attack duration and latency to first attack of resident aggressors during training in Experiment 3

\begin{tabular}{lcc}
\hline Experimental condition & $\begin{array}{c}\text { Latency to } \\
\text { first attack (sec) }\end{array}$ & $\begin{array}{c}\text { Total attack } \\
\text { duration }(\mathrm{sec})\end{array}$ \\
\hline $\begin{array}{l}\text { Saline control (MeA + BLA) } \\
\text { Anisomycin (MeA + BLA) }\end{array}$ & $63.3 \pm 22.2$ & $210.5 \pm 26.7$ \\
\hline
\end{tabular}

volving olfactory cues occurs in the BLA. Cousens and Otto (1998) showed that pre- and post-training neurotoxic (NMDA) lesions of the BLA blocked both conditioned freezing to a (nonbiologically relevant) olfactory CS as well as to the training context. More recently, Kilpatrick and Cahill (2003) showed that animals that received intra-BLA infusions of tetrodotoxin (TTX) following paired odor-shock presentations caused a disruption in memory consolidation when tested $48 \mathrm{~h}$ later in an open-field, place-preference test. The findings in Experiment 3 are also consistent with the Walker (2005) study showing that while infusion of the glutamate receptor antagonists AP5 into the BLA disrupted the acquisition of fear-potentiated startle, AP5 and NBQX failed to reduce FPS when infused into the MeA. These findings suggest that while the BLA is necessary for both the acquisition and expression of FPS, the MeA may only be required for the expression of this behavior. Our findings suggest a similar mechanism. While muscimol disrupted both the acquisition and expression of conditioned defeat, the disruption of protein synthesis via the infusion of anisomycin resulted in a reduction in conditioned defeat only when injected into the BLA, suggesting that plasticity related to odor cues occurs here, rather than in the MeA.

In summary, the findings from the present series of experiments add to the growing body of knowledge regarding the neural mechanisms of conditioned defeat and show for the first time that the MeA may function as a sensory gateway for olfactory stimuli related to biologically relevant odors. We also demonstrated that plasticity for conditioned defeat occurs specifically in the BLA, via its connectivity to the MeA.

\section{Materials and Methods}

\section{Animals and housing conditions}

Subjects were adult male Syrian hamsters (Mesocricetus auratus; Charles River Laboratories, Wilmington, MA) that weighed 110$135 \mathrm{~g}$ and were $\sim 9 \mathrm{wk}$ old at the time of testing. All subjects were individually housed for $2 \mathrm{wk}$ prior to the start of testing in a temperature $\left(20^{\circ} \pm 2^{\circ} \mathrm{C}\right)$ and humidity-controlled room with free access to food and water and kept on a 14:10 h light:dark cycle (lights out at 11:00 h). Resident aggressors (RA) used for defeat training were older ( $>6 \mathrm{mo}$ ), singly housed males weighing between 160 and $180 \mathrm{~g}$. Younger males $(2 \mathrm{mo})$ that weighed between 100 and $110 \mathrm{~g}$ and group-housed (five to six per cage) were used as non-aggressive intruders (NAI). The cages of the experimental animals and the resident aggressors were not changed for 1 wk prior to testing. No RA or NAI was used more than twice on the respective test days. All procedures and protocols were approved by the Georgia State University Institutional Animal Care and Use Committee.

\section{Surgical procedures}

Subjects were anesthetized with sodium pentobarbital $(90 \mathrm{mg} / \mathrm{kg}$, i.p.) and placed into a stereotaxic frame. Two 4.2-mm-long stainless steel guide cannulas (26-gauge) were implanted bilaterally into the brain and aimed at either the medial amygdala $(0.5 \mathrm{~mm}$ caudal and $\pm 2.4 \mathrm{~mm}$ lateral relative to bregma) or the basolateral amygdala $(0.5 \mathrm{~mm}$ rostral and $\pm 3.4 \mathrm{~mm}$ lateral relative to bregma). In order to prevent damage to the area of interest, the guide cannula was lowered to only $3.9 \mathrm{~mm}$ below dura for the MeA and $2.1 \mathrm{~mm}$ below dura for the BLA. On the day of injection, a 33-gauge injection needle projected $4.2 \mathrm{~mm}$ below the guide cannula, reaching a final depth of $7.6 \mathrm{~mm}$ below dura for the MeA and $6.3 \mathrm{~mm}$ below dura for the BLA. This injection procedure minimizes damage to the injection site. Following surgery, dummy stylets were placed in the guide cannula to help maintain patency. Hamsters were allowed 7-10 d to recover from surgery prior to the start of behavioral testing, and they were handled each day after surgery by gently restraining them and removing and replacing the dummy stylet in order to maintain patency and habituate the subjects to the injection procedure. 


\section{Social defeat and behavioral testing}

The conditioned defeat model has been extensively described elsewhere (Huhman et al. 2003). Briefly, on the day of social defeat training, animals were transported to the testing room and allowed to acclimate to the environment for $1 \mathrm{~h}$. All training and testing sessions were performed during the first $3 \mathrm{~h}$ of the dark phase of the light-dark cycle. Training consisted of one 15-min exposure to the RA in the aggressor's home cage, upon which the RA reliably attacked the experimental hamsters within $60 \mathrm{sec}$. The following day, animals were again transported to the same testing room, and a NAI was placed into its home cage for $5 \mathrm{~min}$. An animal was considered to show conditioned defeat if the subject exhibited an increase in submissive and defensive behaviors and no aggressive behaviors when the NAI was introduced into its home cage. Conversely, a reduction in conditioned defeat was operationally defined as a significant reduction in the expression of submissive and defensive behaviors. In contrast, non-defeated animals typically exhibit minimal submissive behaviors and show high levels of territorial aggression directed toward the NAI. All training and testing sessions were videotaped via a camera mounted overhead. The videotapes were then transferred to a CD-ROM and later scored by an experimentally blind observer using the behavioral scoring program Hindsight (developed by Scott Weiss). The total duration of four classes of behaviors were scored during the test session: (1) social behavior (stretch, approach, sniff, nose touching, and flank marking); (2) non-social behavior (locomotion, exploration, grooming, nesting, feeding, and sleeping); (3) submissive/defensive behaviors (flight, avoidance, tail up, upright, side defense, full submissive posture, stretch attend, head flag, attempted escape from cage); and (4) aggressive behaviors (upright and side offense, chase and attack, including bite).

\section{Drug infusion}

\section{Experiments 1 and 2}

The drug infusion procedure was identical for Experiments 1 and 2. Muscimol (Sigma, $1.1 \mathrm{nmol}$ or $2.2 \mathrm{nmol}$ in $200 \mathrm{~nL}$ of saline) or vehicle control (200 $\mathrm{nL}$ of saline) was infused bilaterally into the MeA or BLA (Experiments 1 and 2) over a 1-min period using a $1-\mu \mathrm{L}$ syringe and Hamilton mini-pump connected to a 33-gauge needle via polyethylene tubing. The needle was kept in place for an additional $1 \mathrm{~min}$ before being removed to ensure complete diffusion of the drug after which the dummy stylet was replaced. Testing began 5 min after drug infusion.

\section{Experiment 3}

Anisomycin (Sigma, $0.75 \mathrm{nmol}$ in $200 \mathrm{~nL}$ of saline) or vehicle control (200 nL of saline) was infused bilaterally into either the MeA or the BLA using the identical procedures as described in Experiments 1 and 2, except that testing began 30 min after drug infusion. Anisomycin has been shown to impair memory by disrupting protein synthesis and therefore blocking consolidation (Bourtchouladze et al. 1998; Schafe and LeDoux 2000).

\section{Site verification}

At the end of each experiment, hamsters were administered an overdose of sodium pentobarbital and infused with $200 \mathrm{~nL}$ of India ink to verify the placement of the needle. They were then perfused transcardially with $10 \%$ buffered formalin. The brains were post-fixed in 10\% buffered formalin for $3 \mathrm{~d}$ before being sectioned on a cryostat. Thirty-micrometer sections were taken and stained with neutral red and coverslipped with DPX. Sections were then examined under a light microscope for placement verification. Only animals with injection sites within $0.3 \mathrm{~mm}$ of the BLA or MeA were included in the statistical analysis. Animals with bilateral injections outside of the BLA or MeA were included in a site control group (anatomical controls). Those with unilateral injections (cannula placements within the appropriate site on one side only) were not included in the data analysis.

\section{Experiment 1: Role of the medial amygdala in the acquisition of conditioned defeat}

The goal of Experiment 1 was to determine whether the temporary inactivation of the MeA using the $\mathrm{GABA}_{\mathrm{A}}$ receptor agonist muscimol would significantly reduce the acquisition of conditioned defeat. Animals $(n=42)$ were matched by weight and randomly assigned to one of three conditions. Hamsters received one of two doses of muscimol (1.1 or $2.2 \mathrm{nmol}$ in $200 \mathrm{~nL}$ of saline) or vehicle control ( $200 \mathrm{~nL}$ of saline) 5 min prior to being placed into the home cage of a resident aggressor for $15 \mathrm{~min}$. On the following day, animals were tested drug-free in their own cage against a non-aggressive intruder for $5 \mathrm{~min}$.

\section{Experiment 2: Role of the medial amygdala on the expression of conditioned defeat}

The goal of Experiment 2 was to determine whether the temporary inactivation of the MeA using muscimol would significantly reduce the expression of conditioned defeat. Animals $(n=40)$ were matched by weight and randomly assigned to one of three conditions and placed into the home cage of the resident aggressor for $15 \mathrm{~min}$. On the following day, animals received one of two doses of muscimol ( $1.1 \mathrm{nmol}$ or $2.2 \mathrm{nmol}$ in $200 \mathrm{~nL}$ of saline) or vehicle control (200 $\mathrm{nL}$ of saline) $5 \mathrm{~min}$ prior to conditioned defeat testing (having a non-aggressive intruder in its cage for 5 $\min )$.

\section{Experiment 3: Effects of anisomycin in the medial amygdala and the basolateral amygdala on the acquisition of conditioned defeat}

The goal of Experiment 3 was to determine whether plasticity related to conditioned defeat occurs in the MeA or the BLA. Animals $(n=44)$ were matched by weight and randomly assigned to one of four conditions. The first group $(n=20)$ consisted of animals with cannulas aimed at the BLA, while the second group $(n=24)$ was cannulated in the MeA. On the day of training, the animals received either the anisomycin or saline alone and were placed into the home cage of a resident aggressor for $15 \mathrm{~min}$. On the following day, animals were tested in their own cage against a non-aggressive intruder for $5 \mathrm{~min}$.

\section{Acknowledgments}

We thank Alisa Norvelle and Lauren Zelinski for their expert technical assistance. This research was supported by the National Institutes of Health grant MH62044 to K.L.H., and in part by The Center for Behavioral Neuroscience, a National Science Foundation Science and Technology Center program under agreement no. IBN-9876754. All procedures were approved by the Georgia State University Animal Care and Use Committee and comply with US law.

\section{References}

Blanchard, D.C. and Blanchard, R.J. 1972. Innate and conditioned reactions to threat in rats with amygdaloid lesions. J. Comp. Physiol. Psychol. 81: 281-290.

Blanchard, D.C. and Blanchard, R.J. 1990. Behavioral correlates of chronic dominance-subordination relationships of male rats in a seminatural situation. Neurosci. Biobehav. Rev. 14: 455-462.

Blanchard, D.C., Sakai, R.R., McEwen, B.S., Weiss, S.M., and Blanchard, R.J. 1993. Subordination stress: Behavioral, brain, and neuroendocrine correlates. Behav. Brain Res. 58: 113-121.

Blanchard, D.C., Spencer, R.L., Weiss, S.M., Blanchard, R.J., McEwen, B.S., and Sakai, R.R. 1995. Visible burrow system as a model of chronic social stress: Behavioral and neuroendocrine correlates. Psychoneuroendocrinology 20: $117-134$.

Blanchard, D.C., Canteras, N.S., Markham, C.M., Pentkowski, N.S., and Blanchard, R.J. 2005. Lesions of structures showing FOS expression to cat presentation: Effects on responsivity to a Cat, Cat odor, and nonpredator threat. Neurosci. Biobehav. Rev. 29: 1243-1253.

Bourtchouladze, R., Abel, T., Berman, N., Gordon, R., Lapidus, K., and Kandel, E.R. 1998. Different training procedures recruit either one or two critical periods for contextual memory consolidation, each of 
which requires protein synthesis and PKA. Learn. Mem. 5: 365-374. Campeau, S., Miserendino, M.J., and Davis, M. 1992. Intra-amygdala infusion of the $\mathrm{N}$-methyl-D-aspartate receptor antagonist AP5 blocks acquisition but not expression of fear-potentiated startle to an auditory conditioned stimulus. Behav. Neurosci. 106: 569-574.

Canteras, N.S. 2002. The medial hypothalamic defensive system: Hodological organization and functional implications. Pharmacol. Biochem. Behav. 71: 481-491.

Cousens, G. and Otto, T. 1998. Both pre- and posttraining excitotoxic lesions of the basolateral amygdala abolish the expression of olfactory and contextual fear conditioning. Behav. Neurosci. 112: 1092-1103.

Davis, M. 2006. Neural mechanisms involved in fear and anxiety measured with fear-potentiated startle. Am. Psychol. 61: 741-756.

Day, D.E., Cooper, M.A., and Huhman, K.L. 2004. Ifenprodil blocks acquisition but not expression of conditioned defeat in Syrian hamsters (Mesocricetus auratus). Abstract Viewer Itinerary Planner. Program No. 426.3. Society for Neuroscience, Washington, DC.

Dielenberg, R.A. and McGregor, I.S. 2001. Defensive behavior in rats toward predatory odors: A review. Neurosci. Biobehav. Rev. 25: 597-609.

Dielenberg, R.A., Hunt, G.E., and McGregor, I.S. 2001. "When a rat smells a cat": The distribution of Fos immunoreactivity in rat brain following exposure to a predatory odor. Neuroscience 104: 1085-1097.

Fanselow, M.S. and LeDoux, J.E. 1999. Why we think plasticity underlying Pavlovian fear conditioning occurs in the basolateral amygdala. Neuron 23: 229-232.

Foster, M.T., Solomon, M.B., Huhman, K.L., and Bartness, T.J. 2006. Social defeat increases food intake, body mass, and adiposity in Syrian hamsters. Am. J. Physiol. Regul. Integr. Comp. Physiol. 290: R1284-R1293.

Gewirtz, J.C. and Davis, M. 1997. Second-order fear conditioning prevented by blocking NMDA receptors in amygdala. Nature 388: 471-474.

Helmstetter, F.J. 1992. Contribution of the amygdala to learning and performance of conditioned fear. Physiol. Behav. 51: 1271-1276.

Huhman, K.L., Moore, T.O., Ferris, C.F., Mougey, E.H., and Meyerhoff, J.L. 1991. Acute and repeated exposure to social conflict in male golden hamsters: Increases in plasma POMC-peptides and cortisol and decreases in plasma testosterone. Horm. Behav. 25: 206-216.

Huhman, K.L., Solomon, M.B., Janicki, M., Harmon, A.C., Lin, S.M., Israel, J.E., and Jasnow, A.M. 2003. Conditioned defeat in male and female Syrian hamsters. Horm. Behav. 44: 293-299.

Jasnow, A.M. and Huhman, K.L. 2001. Activation of GABA $_{\mathrm{A}}$ receptors in the amygdala blocks the acquisition and expression of conditioned defeat in Syrian hamsters. Brain Res. 920: 142-150.

Kilpatrick, L. and Cahill, L. 2003. Modulation of memory consolidation for olfactory learning by reversible inactivation of the basolateral amygdala. Behav. Neurosci. 117: 184-188.

LeDoux, J.E. 2000. Emotion circuits in the brain. Annu. Rev. Neurosci. 23: $155-184$.

LeDoux, J.E., Cicchetti, P., Xagoraris, A., and Romanski, L.M. 1990. The lateral amygdaloid nucleus: Sensory interface of the amygdala in fear conditioning. J. Neurosci. 10: 1062-1069.

Lee, H. and Kim, J.J. 1998. Amygdalar NMDA receptors are critical for new fear learning in previously fear-conditioned rats. J. Neurosci. 18: $8444-8454$.

Lehman, M.N. and Winans, S.S. 1982. Vomeronasal and olfactory pathways to the amygdala controlling male hamster sexual behavior: Autoradiographic and behavioral analyses. Brain Res. 240: 27-41.

Li, C.I., Maglinao, T.L., and Takahashi, L.K. 2004. Medial amygdala modulation of predator odor-induced unconditioned fear in the rat. Behav. Neurosci. 118: 324-332.

Luiten, P.G., Koolhaas, J.M., de Boer, S., and Koopmans, S.J. 1985. The cortico-medial amygdala in the central nervous system organization of agonistic behavior. Brain Res. 332: 283-297.

Maren, S. 2001. Neurobiology of Pavlovian fear conditioning. Annu. Rev. Neurosci. 24: 897-931.

Markham, C.M., Park, Y., Blanchard, R.J., and Blanchard, D.C. 2004 Effects of ibotenic acid lesions of the medial amygdala on unconditioned and conditioned responses to predatory stimuli. Abstract Viewer Itinerary Planner. Program No. 784.6. Society for Neuroscience, Washington, DC.

Meredith, M. and Westberry, J.M. 2004. Distinctive responses in the medial amygdala to same-species and different-species pheromones. J. Neurosci. 24: 5719-5725.

Morin, L.P. and Wood, R.I. 2001. Atlas of the golden hamster brain Academic Press, San Diego.

Muller, M. and Fendt, M. 2006. Temporary inactivation of the medial and basolateral amygdala differentially affects TMT-induced fear behavior in rats. Behav. Brain Res. 167: 57-62.

Nader, K., Majidishad, P., Amorapanth, P., and LeDoux, J.E. 2001. Damage to the lateral and central, but not other, amygdaloid nuclei prevents the acquisition of auditory fear conditioning. Learn. Mem. 8: $156-163$.

Newman, S.W. 1999. The medial extended amygdala in male reproductive behavior. A node in the mammalian social behavior network. Ann. N. Y. Acad. Sci. 877: 242-257.

Oakes, M.E. and Coover, G.D. 1997. Effects of small amygdala lesions on fear, but not aggression, in the rat. Physiol. Behav. 61: 45-55.

Parsons, R.G., Gafford, G.M., Baruch, D.E., Riedner, B.A., and Helmstetter, F.J. 2006. Long-term stability of fear memory depends on the synthesis of protein but not mRNA in the amygdala. Eur. J. Neurosci. 23: 1853-1859.

Phillips, R.G. and LeDoux, J.E. 1992. Differential contribution of amygdala and hippocampus to cued and contextual fear conditioning. Behav. Neurosci. 106: 274-285.

Potegal, M., Huhman, K.L., Moore, T., and Meyerhoff, J.L. 1993. Conditioned defeat in the Syrian golden hamster. Behav. Neural Biol. 60: $93-102$.

Rattiner, L.M., Davis, M., French, C.T., and Ressler, K.J. 2004 Brain-derived neurotrophic factor and tyrosine kinase receptor B involvement in amygdala-dependent fear conditioning. J. Neurosci. 24: $4796-4806$

Rodrigues, S.M., Schafe, G.E., and LeDoux, J.E. 2001. Intra-amygdala blockade of the NR2B subunit of the NMDA receptor disrupts the acquisition but not the expression of fear conditioning. J. Neurosci. 21: 6889-6896.

Roozendaal, B., Koolhaas, J.M., and Bohus, B. 1991. Central amygdala lesions affect behavioral and autonomic balance during stress in rats Physiol. Behav. 50: 777-781.

Sananes, C.B. and Davis, M. 1992. N-Methyl-D-aspartate lesions of the lateral and basolateral nuclei of the amygdala block fear-potentiated startle and shock sensitization of startle. Behav. Neurosci. 106: 72-80.

Schafe, G.E. and LeDoux, J.E. 2000. Memory consolidation of auditory Pavlovian fear conditioning requires protein synthesis and protein kinase A in the amygdala. J. Neurosci. 20: RC96.1-RC96.5.

Solomon, M.B., Foster, M.T., Bartness, T.J., and Huhman, K.L. 2007. Social defeat and footshock increases body mass and adiposity in male Syrian hamsters. Am. J. Physiol. Regul. Integr. Comp. Physiol. 292: R283-R290.

Tang, Y.P., Shimizu, E., Dube, G.R., Rampon, C., Kerchner, G.A., Zhuo, M., Liu, G., and Tsien, J.Z. 1999. Genetic enhancement of learning and memory in mice. Nature 401: $63-69$.

Walker, D.L., Paschall, G.Y., and Davis, M. 2005. Glutamate receptor antagonist infusions into the basolateral and medial amygdala reveal differential contributions to olfactory vs. context fear conditioning and expression. Learn. Mem. 12: 120-129.

Received September 7, 2007; accepted in revised form November 1, 2007. 


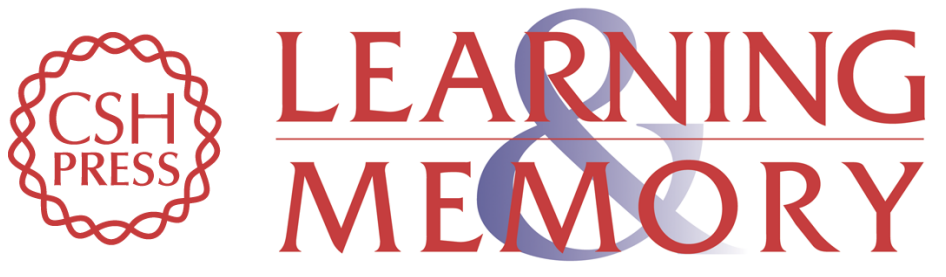

\section{Is the medial amygdala part of the neural circuit modulating conditioned defeat in Syrian hamsters?}

Chris M. Markham and Kim L. Huhman

Learn. Mem. 2008, 15:

Access the most recent version at doi:10.1101//m.768208

References This article cites 43 articles, 8 of which can be accessed free at: http://learnmem.cshlp.org/content/15/1/6.full.html\#ref-list-1

License

Email Alerting Receive free email alerts when new articles cite this article - sign up in the box at the Service top right corner of the article or click here. 